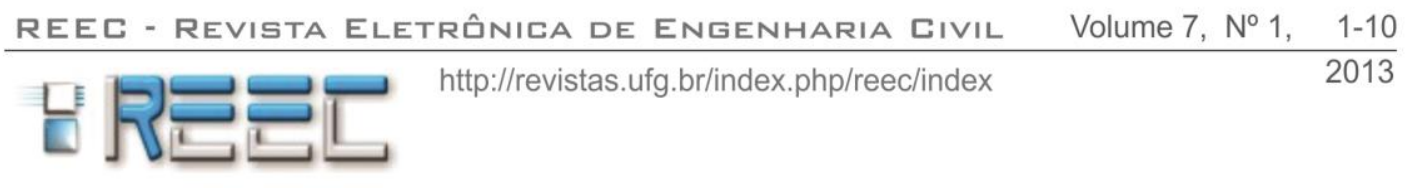

\title{
O PAPEL DO SEDIMENTO NA QUALIDADE DA ÁGUA DE ABASTECIMENTO URBANO: UMA REVISÃO DOS TRABALHOS PUBLICADOS ENTRE 2001 E 2011
}

\section{THE ROLE OF SEDIMENT IN URBAN WATER SUPPLY QUALITY: A REVIEW OF PUBLISHED PAPERS SINCE 2001 TO 2011}

\author{
Laís S. de Moura ${ }^{1}$; Rafaela J. de O. Braga ${ }^{2}$; Elisa R. Siqueira ${ }^{3}$ e Katia A. Kopp ${ }^{4}$
}

Recebido em 25 de fevereiro de 2013; recebido para revisão em 28 de março de 2013; aceito em 30 de março de 2013; disponivel on-line em 21 de abril de 2013.

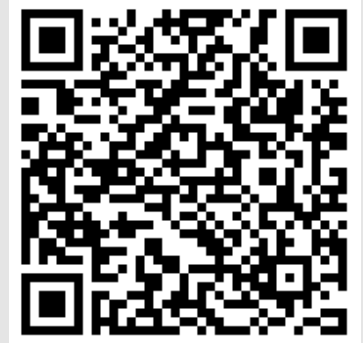

\section{PALAVRAS CHAVES:}

Qualidade da água;

Sedimento;

Poluição hídrica.

\section{KEYWORDS:}

Water quality;

Sediment;

Water pollution.

\section{* Contato com os autores:}

${ }^{1}$ e-mail : lais.simoes.moura@gmail.com

(L. S. de Moura)

Química Industrial aluna do Prog. de Pós-graduação em Eng. do Meio Ambiente (PPGEMA) da Universidade Federal de Goiás (UFG)

2e-mail : rafaelajacob@gmail.com

(R. J. de O. Braga)

Bióloga aluna do Prog. de Pós-graduação em Eng. do Meio Ambiente (PPGEMA) da Universidade Federal de Goiás (UFG)

${ }^{3}$ e-mail : rodrigues.siqueira@gmail.com (E. R. Siqueira)

Engenheira Ambiental aluna do Prog. de Pós-graduação em Eng. do Meio Ambiente (PPGEMA) da Universidade Federal de Goiás (UFG)

${ }^{4}$ e-mail : kakopp@gmail.com (K. A. Kopp)

Bióloga Professora Dra. do curso de Engenharia Ambiental da Universidade Federal de Goiás (UFG) e sedimento é considerado como um carreador e fixador de

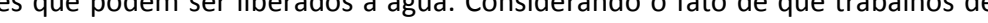
artigos publicados que abordaram esse tema durante os dez últimos anos (2001 - 2011). Foram encontrados 812 trabalhos na base de dados "Web of Science" e eles foram analisados em cinco frentes diferentes: ano de publicação, linguagem em que foram publicados, países de dos autores, locais em que esses artigos foram publicados e áreas de pesquisa em que é Unidos foi o país que mais publicou artigos dessa temática e, consequentemente, a quase dos trabalhos foram publicados na língua inglesa e a ecologia e as ciências contribuição do Brasil nas pesquisas dessa área e a carência que o país tem em relação a

ABSTRACT: Studies considering the role of sediment in determining the quality of water are becoming increasingly common. The growing interest in studies of this area can be justified by increasing worldwide concern for ensuring quality water for human consumption, since the Considering the fact that revision work are guiding and even encouraging research, we did a review of published articles that addressed this issue during the last ten years (2001 - 2011). (ne database "Web of Science" and they were analyzed in five countries of origin, places where these articles were published and research areas that this is the amount of sediment publications relating to published in this issue, and therefore almost all the papers were published in the language

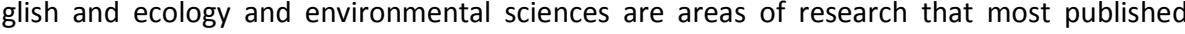
these articles. It was also found Brazil's contribution in this research area and the shortage that the country has in relation to research within the environment.

RESUMO: Estudos considerando o papel do sedimento na determinação da qualidade da água 


\section{INTRODUÇÃO}

A água é um recurso natural e de fundamental importância para o desenvolvimento e manutenção de qualquer forma de vida e, por isso, é necessário preservá-la para que seu uso e consumo aconteçam de forma eficiente e sustentável. Entretanto, a maioria das pessoas acredita que ela é reposta com a ocorrência do seu ciclo natural, mas considerando os fatores que interferem no ciclo hidrológico, logo se percebe que na prática essa total recuperação não é observada (Souza, 2007).

Dentre as várias funções desempenhadas pela água doce, tem-se a de abastecimento. A água de microbacias que é destinada ao consumo humano deve atender a um padrão de qualidade que é composto por parâmetros. Estes são essenciais em conferir qualidade à água que será consumida pela população (Brasil, 2006).

Nesse sentido é indispensável que se realize análises laboratoriais por amostragem como também o gerenciamento dos riscos e impactos apresentados por todas as etapas do seu fornecimento com o objetivo de verificar as interferências existentes em seu percurso que possam comprometer a qualidade da água garantindo, assim, os padrões de potabilidade exigidos pela Portaria no 2914/2011 (Brasil, 2011).

Segundo a Organização Mundial da Saúde (WHO, 2004), diagnosticar, avaliar e gerir os riscos apresentados desde a captação da água no manancial até o seu consumo, são mecanismos efetivos para a garantia da qualidade da água ao homem, prevenindo a disseminação de doenças de veiculação hídrica que comprometem a saúde humana. Porém, essas ações devem acontecer de forma rotineira e preventiva.

A mesma organização recomenda ainda que as entidades responsáveis por gerir os sistemas de abastecimento de água devem elaborar e executar metodologias voltadas para a prevenção de riscos e boas práticas de operação dos sistemas com o intuído de assegurá-la em padrões de potabilidade para o consumidor (WHO, 2004).

Entretanto, embora a água destinada ao consumo humano deva ser resguardada em relação à contaminação, já que será ingerida, isso não é o suficiente para garantir o seu atendimento aos padrões exigidos pela legislação. Isso porque esse recurso acaba sendo o destino final de contaminantes presentes em várias fontes, como pesticidas, água de irrigação contaminada, queima de biomassa, combustão de carvão e óleo, emissões veiculares (Tavares e Carvalho, 1992) e incineração de resíduos urbanos e industriais
(Coelho et al., 2002).

A maioria dos corpos hídricos está sujeita à contaminação por várias fontes pontuais e difusas, como por exemplo, despejo de efluentes industriais não tratados e resíduos de agrotóxicos. A presença de matadouros, vários tipos de indústrias, rodovias, a proximidade com o meio urbano e até mesmo de terras destinadas à agricultura nas encostas dessas microbacias pode estar alterando as características físicas, químicas e microbiológicas desse ambiente, ocasionando problemas que podem, às vezes, ser reconhecidos apenas em longo prazo.

Os resíduos descartados que acabam tomando o rumo dos rios podem estar presentes na água e nos sedimentos, que são as camadas de partículas minerais e orgânicas finamente granuladas que estão em contato com a parte inferior dos corpos d'água naturais (Costa et al., 2008) e usualmente, são uma mistura complexa de minerais, matéria orgânica e componentes biológicos (Franzen, 2009). De uma forma mais literal, o sedimento também é conhecido como aquilo que está disponível para o transporte, algo que se deposita ou depositou e até mesmo o que é passível de se depositar (Trindade, 2010). Isso mostra a mobilidade a que os compostos presentes nesse meio estão sujeitos, além de chamar a atenção para a possibilidade da sua liberação por tempo indeterminado para a coluna d'água sem que se perceba (Jardim, 2004).

É no sedimento dos ambientes aquáticos onde ocorrem todos os processos (sendo eles físicos, químicos e microbiológicos) relacionados a esse meio. Esses processos estão ligados diretamente à produtividade do ecossistema aquático e também terrestre. Eles não são importantes apenas para a ocorrência dos processos, mas no estudo da evolução histórica e armazenamento de elementos conservativos. Sem esquecer que também são necessários nos estudos e avaliações da intensidade e forma de impactos a que os ecossistemas aquáticos estiveram ou estão submetidos (Sampaio, 2003).

Portanto, quando contaminado com metais pesados ou agrotóxicos, por exemplo, o sedimento exerce efeitos drásticos aos ecossistemas no qual está inserido. A exposição direta dos seus contaminantes para os organismos é considerada uma importante rota de transferência para muitas espécies. Dessa forma, concentrações iguais de um determinado contaminante presente em sedimentos diferentes apresentam efeitos de toxicidade diferentes, onde determinando sedimento pode ser altamente tóxico para um tipo de organismo enquanto o outro tipo de sedimento com a mesma concentração desse contaminante não apresente 
toxicidade ao mesmo (Jardim, 2004).

Os sedimentos já são reconhecidos como importantes repositórios de poluentes no ecossistema aquático. Esse acúmulo de contaminantes pode ocorrer por vários mecanismos, como por exemplo, floculação e precipitação direta, adsorção no material particulado e deposição no fundo. Dessa forma, a contaminação dos sedimentos também é vista como um importante indicador ambiental de poluição, sendo um auxiliar tanto no monitoramento de fontes antropogênicas de poluição como de anormalidades nos processos geoquímicos naturais (Hortelanni et al, 2005).

Ele não é o maior poluidor dos corpos hídricos, mas pode atuar como catalisador, carreador e agente fixador de agentes poluidores. Sozinho, ele pode degradar a qualidade da água para a vida aquática e, consequentemente, para o consumo humano, pois produtos químicos podem ser assimilados sobre e dentro de suas partículas mais finas (Carvalho et al., 2000). Assim, a importância do estudo da concentração de metais nesse ambiente, por exemplo, não pode ser descartada, já que concentrações específicas desses elementos são extremamente tóxicas e a sua acumulação pode provocar graves doenças, sobretudo nos mamíferos (Ferreira, Horta e Cunha, 2010). Considerando que os corpos hídricos funcionam como destino final de vários contaminantes e conhecendo a definição de sedimento, constata-se que nem sempre apenas as análises da água garantirão que ela atenda aos padrões exigidos para o seu uso como abastecimento, já que alguns contaminantes podem estar adsorvidos na superfície desses sedimentos. Por isso, o estudo e a determinação das características físicas e químicas dele estão conseguido cada vez mais importância diante da determinação da qualidade da água que será consumida pela população (Cetesb, 2006).

Neste contexto, a necessidade de monitoramento dos sedimentos provenientes de microbacias hidrográficas cuja água é destinada ao abastecimento é tão importante quanto o monitoramento desse recurso hídrico, pois os sedimentos podem adsorver produtos químicos e, desta forma, peixes, aves, e até o homem podem se contaminar (Arine, 2000). Os sedimentos são importantes na avaliação do nível de contaminação dos ecossistemas aquáticos não apenas pela capacidade em acumular elementos-traço, mas também por transportar e ser prováveis fontes de contaminação, já que podem liberar tais espécies químicas para a água (Balls, 1989 apud Sousa, 2009).

\section{OBJETIVO}

Considerando a importância da determinação da qualidade do sedimento em relação à atribuição de qualidade da água que será utilizada para o abastecimento público, o objetivo desse trabalho foi realizar uma análise quantitativa temporal do número de trabalhos publicados, conforme a metodologia de "mapping study", de forma a classificar, mapear e relacionar o papel do sedimento na contribuição da qualidade da água.

\section{METODOLOGIA}

A metodologia utilizada nesse trabalho é conhecida como Mapping Study e as buscas aconteceram de forma virtual.

Utilizando a rotina "General Search" da base de dados Web of Science presente no portal de periódicos da Capes fez-se uma busca dos trabalhos que citavam os termos "quality water", "sediment" e "pollution" no tópico e/ou tema.

A busca foi realizada da seguinte forma: nos três campos disponíveis para a escrita dos termos que serão buscados, escreveram-se os termos escolhidos (citados no parágrafo anterior) e selecionou-se a categoria TOPIC no campo de pesquisa (opção presente logo à frente de onde se escreve o termo que será buscado) para os três (Ex: "Water Quality" in Topic AND "Sediment" in Topic AND "Pollution" in Topic).

Há vários operadores de busca, como AND, OR, NOT e SAME e cada um deles direcionará a busca de uma maneira diferente. Nesse trabalho, o operador "AND" foi utilizado para que tanto o termo "quality water" quanto os termos "sediment" e "pollution" fossem encontrados nos registros da base de dados escolhida.

Seguindo as opções presentes na página, a busca foi refinada apenas para artigos publicados entre os anos de 2001 e 2011 (fazendo com que a pesquisa compreendesse um período de publicação de dez anos) no campo chamado "Current Limits".

Foram obtidas as informações a seguir descritas: I - ano de publicação, II - linguagem dos trabalhos publicados, III - país de origem dos trabalhos publicados, IV - locais de publicação e V - áreas de pesquisa em que esse tema abrange. Após a obtenção desses dados, gráficos foram montados e os resultados foram discutidos. 


\section{RESULTADOS E DISCUSSÃO}

Após o levantamento dos dados de interesse para o estudo, foram encontrados 812 artigos utilizando os termos "water quality", "sediment" e "pollution".

O gráfico mostrado na Figura 1 contabiliza o número de publicações referentes a esse tema, no período de 2001 a 2011. Analisando-o, pode-se observar que o interesse de pesquisa nesta área vem crescendo a cada ano. Em 2001 foram 39 artigos publicados enquanto que no ano de 2011 esse número foi de 116, o que representa um aumento de $66 \%$ neste intervalo de tempo. Este incremento pode ser associado ao aumento da preocupação com a qualidade da água em todo o mundo, sendo que o sedimento representa um papel importante como indicador de poluição e para o monitoramento dos corpos hídricos (Mortatti, Hissler e Probst, 2010).

Das 812 publicações encontradas, $98 \%$ estão escritas no idioma inglês $(n=802)$. $O$ francês e o espanhol tiveram três publicações cada, enquanto que na língua portuguesa, foram encontradas duas publicações (Figura 2).

A língua inglesa é um instrumento de comunicação mundial e muitos países já a adotam como primeira língua estrangeira ao mesmo tempo em que é utilizada como língua franca na produção de trabalhos científicos e na comercialização internacional (Silva, 2009).

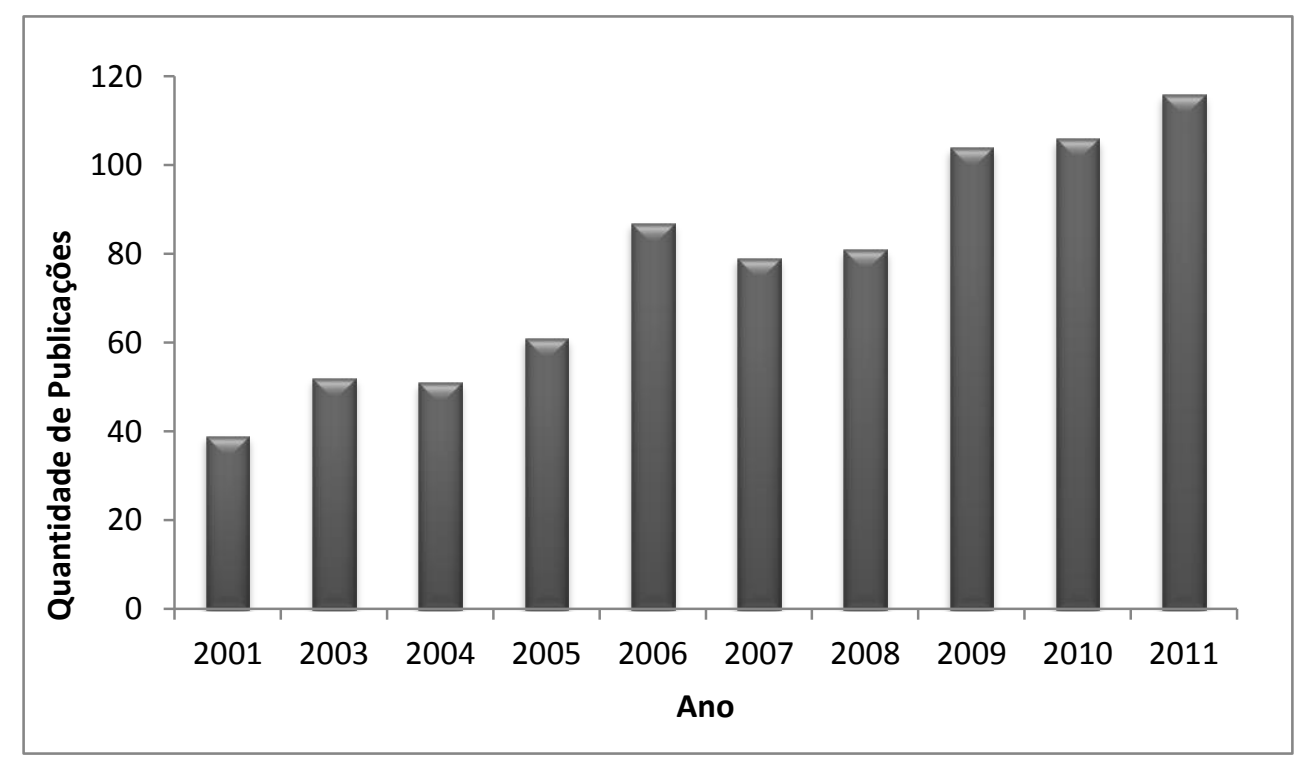

Figura 1: Número de trabalhos publicados ( $n=812$ ), no período de 2001 a 2011, com os termos "water quality", "sediment", "pollution".

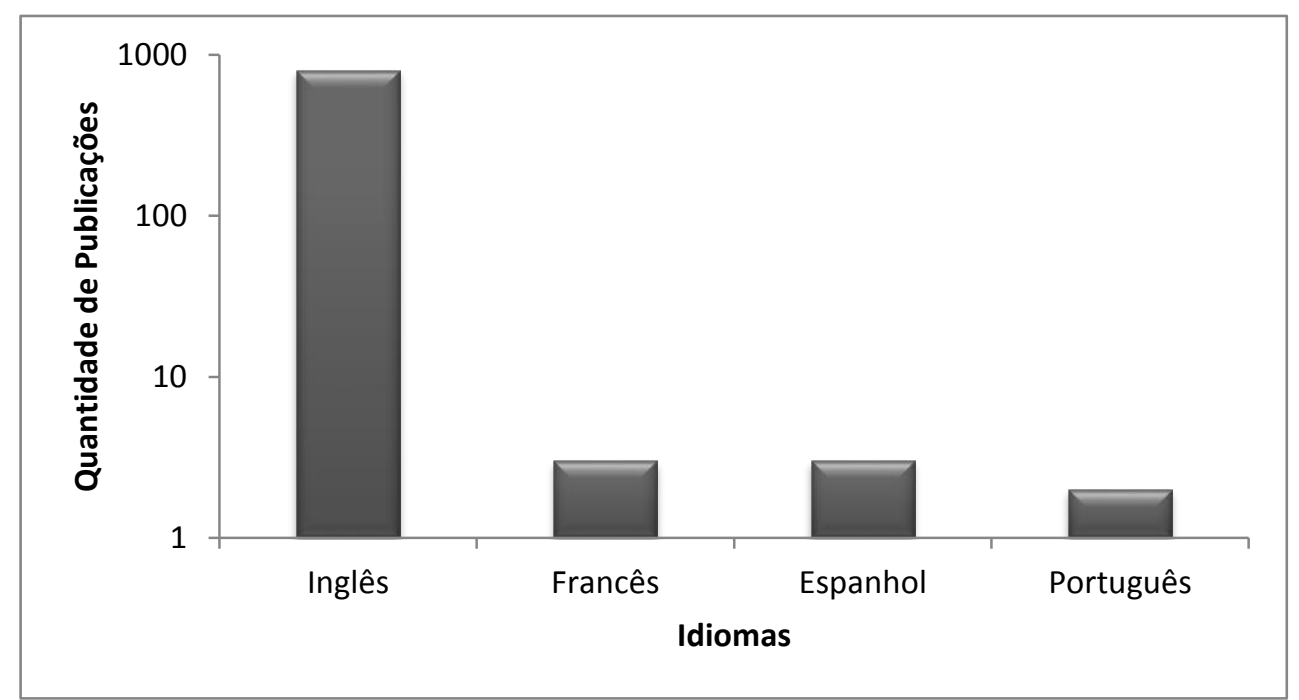

Figura 2: Idiomas adotados nas publicações, no período de 2001 a 2011, com os termos "water quality", "sediment", "pollution". 
Os Estados Unidos foram responsáveis pela maioria dos artigos publicados, representando $42 \%$ ( $n=343)$, seguido da China com 8,8\% $(n=72)$. O Brasil foi responsável por 2,7\% $(n=22)$ das publicações (Figura 3). Segundo o Relatório Knowledge, Networks and Nations: Global scientific collaboration in the $21^{\text {ST }}$ century, publicado em 2011 e produzido pela Royal Society, a academia de ciências do Reino Unido, embora os Estados Unidos ainda continuem na liderança em termos de investimentos e pesquisas realizadas, o mundo científico está mudando e novos atores estão surgindo. Na China, o investimento em pesquisa e desenvolvimento tem crescido a uma média de $20 \%$ ao ano desde 1999, chegando aos US\$ 100 bilhões (ou 1,44\% do PIB) em 2007, e o país pretende investir ainda mais, alcançando um investimento no setor de $2,5 \%$ do PIB até 2020 . O Brasil, na linha de sua aspiração de se tornar uma 'economia do conhecimento natural', com base em seus recursos naturais e ambientais, está trabalhando para aumentar o investimento em pesquisa de $1,4 \%$ do PIB, em 2007, para 2,5\%, em 2022 (The Royal Society, 2011).

A comunidade científica mundial está sendo cada vez mais impulsionada pela necessidade de encontrar soluções para uma série de questões que ameaçam a sustentabilidade. Estes desafios globais tem recebido muita atenção nos últimos anos e agora são componentes essenciais nas estratégias nacionais e multinacionais da ciência e de mecanismos de financiamento (The Royal Society, 2011).
No período compreendido entre os anos de 2001 e 2011, o Brasil mostra-se incipiente em publicações que associam esses termos quando comparados a países como o EUA, China, Inglaterra, Canadá, Austrália e Turquia. Todavia, um dos artigos escritos por autores brasileiros é intitulado como "Blue rayon e teste Salmonella/microssoma na avaliação da qualidade de águas costeiras" e foi publicado no ano de 2006. Nele, os autores escolheram dois pontos de amostragem no estuário de Santos, em São Paulo, para coletar o sedimento que desconfiavam estar contaminado com hidrocarbonetos policíclicos aromáticos e também por compostos genotóxicos. Concluíram que o sedimento dos dois pontos amostrados estava contaminado e que a técnica de blue rayon combinada com o ensaio usando a Salmonella conseguiu recuperar os contaminantes que estavam presentes no sedimento (Kummrow et al, 2006).

Outro artigo também escrito por brasileiros foi "Variabilidade espacial e sazonal da concentração de elementos-traço em sedimentos do sistema estuarino de Santos-Cubatão (SP)", publicado também em 2006. Nesse trabalho, os autores avaliaram a variação espacial e temporal das concentrações de elementos-traços, como chumbo, níquel, cobre e alumínio (até mesmo os mais tóxicos, por exemplo, mercúrio e cádmio) no sedimento do sistema estuarino de Santos-Cubatão. Eles concluíram que o sedimento dos pontos coletados alcançou níveis de concentração dos elementos

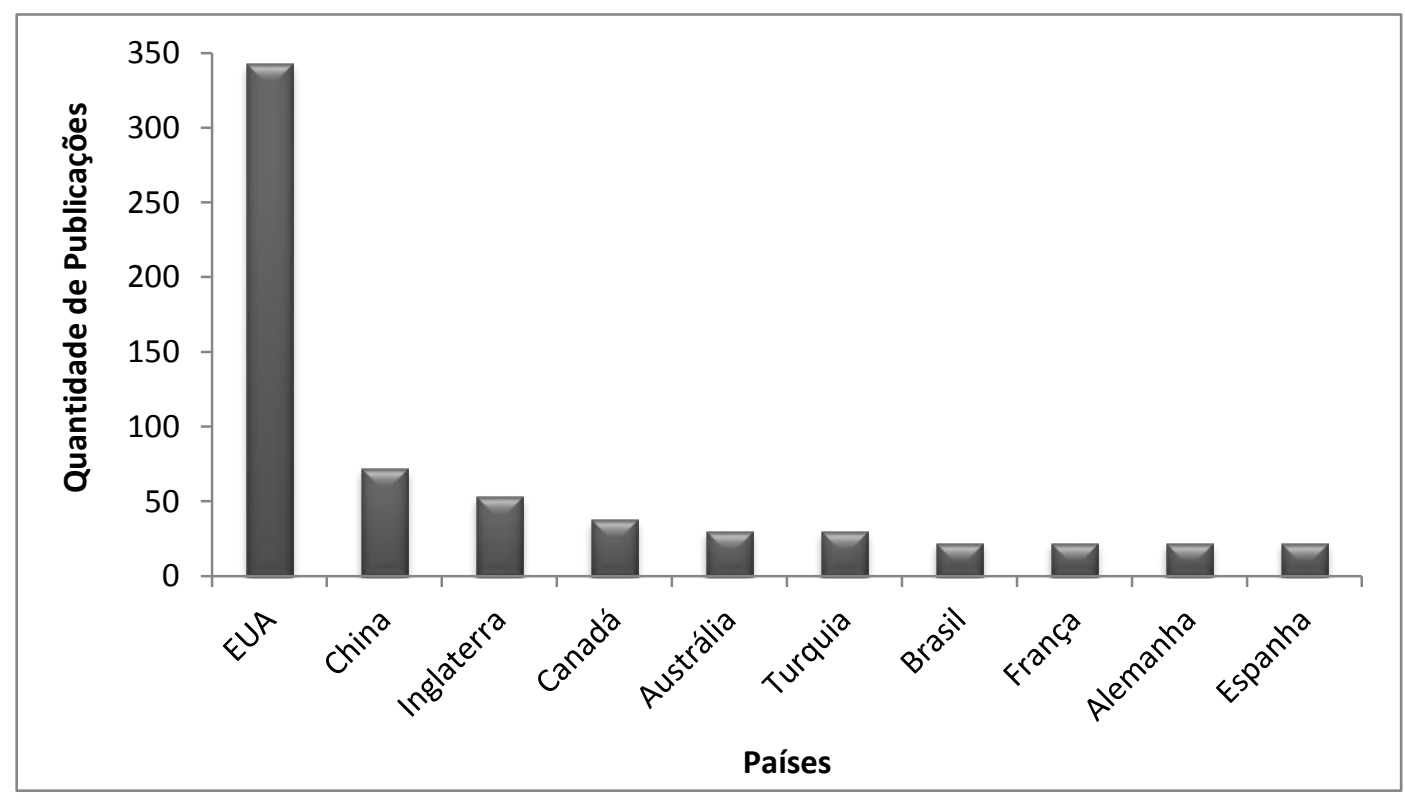

Figura 3: Países que mais publicaram, no período de 2001 a 2011, com os termos "water quality", "sediment", "pollution". 
avaliados que podem afetar o equilíbrio do ecossistema local e que a sazonalidade fornece resultados que não podem ser desconsiderados. Estudos como esses devem ser fomentados e incentivados para que discussões e legislações sobre o tema sejam mais eficazes (Silva et al, 2006).

O gráfico representado na Figura 4 aborda a relação entre as principais áreas do conhecimento e a quantidade de publicações referentes ao assunto. 0 destaque maior é dado às áreas da Ecologia e Ciências Ambientais ( $n=492)$, Recursos Hídricos $(n=288)$ e Engenharia ( $n=190)$ que, juntas, correspondem com um total de 970 publicações entre os anos analisados.

A crescente preocupação com as questões ambientais entre o período de 2001 e 2011 é constatada pela quantidade significativa de publicações nessa área do conhecimento. Todavia, o histórico de atenção em relação ao meio ambiente surgiu bem antes dessas datas.

Esse fato se confirma através da publicação do livro Primavera Silenciosa em 1962 em que a autora, Rachel Carson, discutiu sobre a transferência do DDT (Dicloro-Difenil-Tricloroetano) através dos níveis tróficos das cadeias alimentares e como esse composto pode comprometer a saúde dos seres vivos devido a sua capacidade de acumulação.

Dez anos após a publicação do livro, houve o reconhecimento pela Organização das Nações Unidas (ONU) sobre a intensa exploração dos recursos naturais e as possíveis consequências ao meio e a saúde humana através das discussões apresentadas na Conferência de Estocolmo em 1972. Após 20 anos da respectiva conferência em que houve um aprofundamento no assunto sobre os impactos ambientais gerados pela ação antrópica e quais as ações que deveriam ser adotadas para conter o comprometimento do meio ambiente, surgiu a Eco Rio 92 discutindo ainda mais o conceito de sustentabilidade e a proposição da Agenda 21 (Barbosa, 2008).

Em 2012, reforçando ainda mais a importância de se estudar e conhecer o meio ambiente ocorreu no Brasil a Conferência Rio +20 . Ela objetivou destacar a importância e a necessidade de adoção de práticas sustentáveis em todos os países para que a sadia qualidade de vida seja alcançada, que os níveis de degradação ambiental diminuam e que as ações de preservação e recuperação de áreas degradadas sejam mantidas e aumentadas.

Já o destaque dado aos recursos hídricos assim como a engenharia é verificado quando se observa a preocupação em garantir à população água com qualidade e em quantidade satisfatória para a manutenção da vida. Entretanto, para que essa situação aconteça com eficiência é necessário usufruir sustentavelmente dos ecossistemas terrestres e aquáticos. Esse usufruto consciente acontece através das intervenções antrópicas que valorizam os recursos atuais e os tornam disponíveis com a mesma, ou em melhor propriedade, para as próximas populações.

A preocupação com a qualidade da água passou a ser discutida a partir do momento em que foi possível constatar que muitas doenças predominantes no século XIX, a exemplo a cólera e febre tifoide, eram causadas por microorganismos patogênicos presente na água. Essas situações promoveram mudanças na forma como ela era gerenciada, já que até então era restrita as suas propriedades organolépticas (Viera et al., 2005 apud Ceballos, Daniel e Bastos, 2009; Pato, 2011; Hilaco, 2012).

Outro quesito que se destaca nesse mesmo período é a notoriedade do crescimento dos centros urbanos, pois além de expor a população a riscos, o desenvolvimento do saneamento básico e a disponibilidade hídrica não acompanham o crescimento das cidades comprometendo a água utilizada como fonte de abastecimento (Viera et al., 2005 apud Ceballos, Daniel e Bastos, 2009; Pato, 2011; Hilaco, 2012).

Todavia, sabendo do comprometimento dos aquíferos em relação a sua qualidade e o esgotamento dos mesmos, são necessárias intervenções de preservação nesse ambiente como também investimentos em pesquisa e desenvolvimento tecnológico para que a utilização da água seja viável, racional e sustentável (Paz, Teodoro e Mendonça, 2000).

Quando se trata de água para abastecimento público, o nível de exigência em relação a sua qualidade é maior. Água com qualidade é aquela livre de agentes patogênicos, substâncias químicas e radioativas que possam de forma direta ou bioacumulativa, causarem 
transtornos à saúde pública, devido a sua toxicidade. Essa situação mostra que é necessário incentivar pesquisas e ao mesmo tempo torná-las públicas no que tange a área de conhecimento interligada às Ciências Ambientais e Ecologia como a Saúde Pública Ambiental Ocupacional.

Outra situação também inferida pelo gráfico é que a área de conhecimento Toxicologia apresenta uma pequena quantidade de publicação entre os anos analisados. Ela apresenta destaque apenas quando comparada com a área Oceanografia e Saúde Pública Ambiental Ocupacional. É necessário incluir e discutir com afinco as questões toxicológicas para todos os seres pertencentes a um ecossistema de comunidades aquáticas e comunidades terrestres e também abordá-la em quanto à saúde humana, já que todos estão sujeitos em maior ou em menor concentração à agentes toxicológicos. O predomínio da língua inglesa é refletido também nos locais de publicação independente da tipologia (revista, simpósio, conferência, congresso, entre outros). Essa relevância só ressalta ainda mais a hegemonia Norte Americana (EUA) em relação à quantidade de publicações entre os anos de 2001 e 2011 (Figura 5).

A predominância do inglês também é destacada pelo imperialismo linguístico promovido pelos movimentos de globalização. Ela ainda é a língua franca para as ciências da natureza (Ortiz, 2004).

Vale ressaltar que entre os locais de publicação, a Reunião Anual da Sociedade Americana de Engenheiros Agrícolas apresenta o maior número entre o período de 2001 a 2011, registrando quatro publicações.

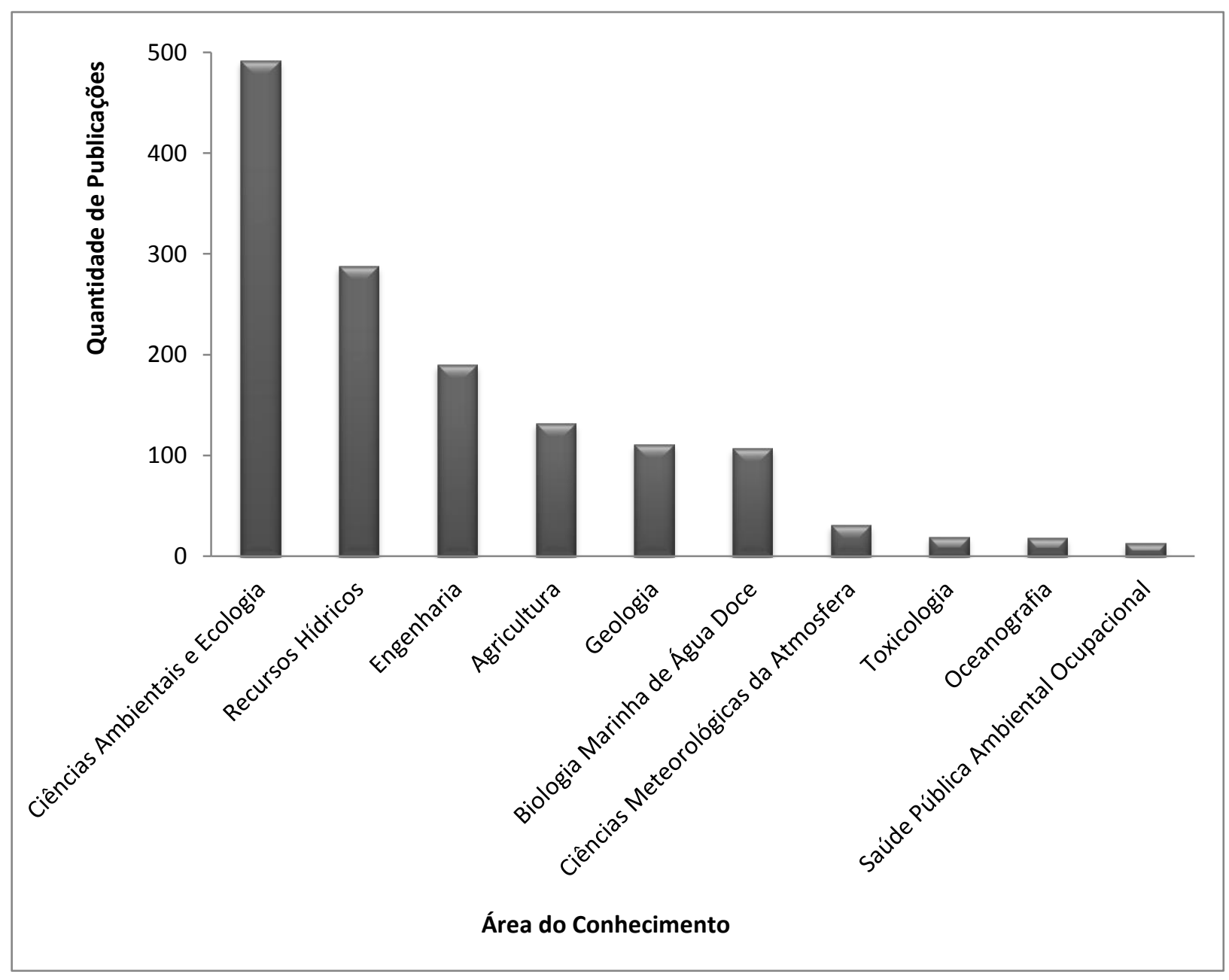

Figura 4: Relação entre a quantidade de publicações entre os anos de 2001 a 2011 e respectivas áreas do conhecimento. 


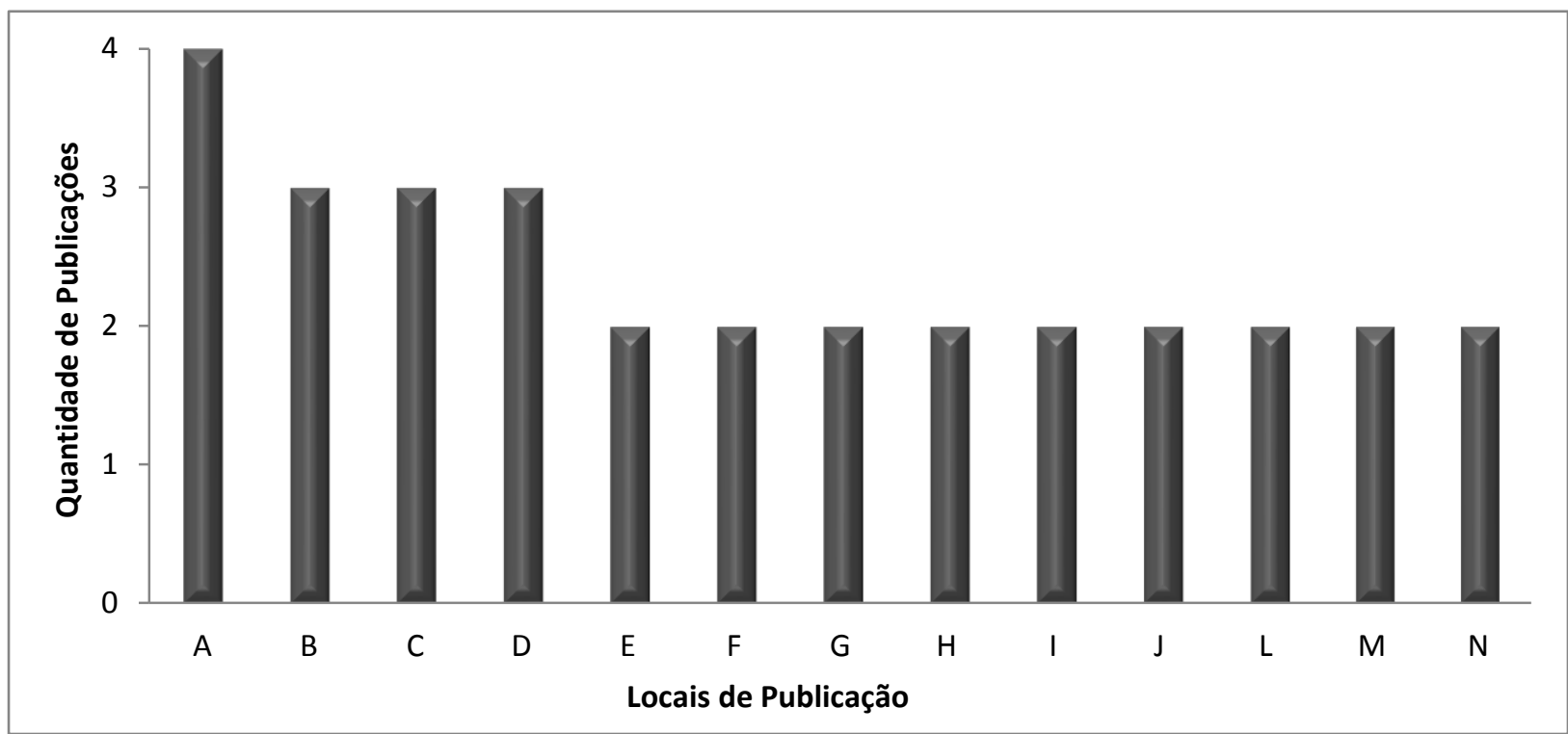

Figura 5: Relação entre a quantidade e locais de publicações entre os anos de 2001 a 2011.

\section{LEGENDA:}

A - Annual Meeting of the American Society of Agricultural Engineers.

B - $10^{\text {th }}$ IWA Specialist Conference on Watershed and River Basin Management.

C - $1^{\text {st }}$ International Conference on Diffuse Pollution.

D - Conference for Reef Research.

E - $13^{\text {th }}$ IWA International Specialist Conference on Diffuse Pollution and Integrated Watershed Management.

F - $1^{\text {st }}$ World Water Congress on the International Water Association.

G $-25^{\text {th }}$ International Symposium of the North American Lake Management Society.

$\mathbf{H}-5^{\text {th }}$ International Conference on Marine Pollution and Ecotoxicology.

I - $6^{\text {th }}$ Waternet Warfsa GWA SA Symposium.

J - $9^{\text {th }}$ IWA International Conference on Diffuse Pollution.

L - ASAE International Meeting.

M - International Symposium on the Eutrophication Process and Control in Large Shallow Lakes.

$\mathbf{N}$ - Workshop on Efficiency of Purification Processes in Riparian Buffer Zones.

\section{CONCLUSÕES}

A pesquisa realizada encontrou 812 artigos que citavam os termos "water quality", "sediment" e "pollution" na base de dados Web of Science. Como o estudo foi delimitado para resultados de artigos e usouse apenas uma base de dados, os resultados encontrados se diferenciam dos que poderiam ser obtidos caso tivessem sido consideradas também outras bases de dados e determinado outra faixa de anos de publicação.

A análise cienciométrica de dados é importante no que tange a necessidade de descobrir e documentar informações referentes à quantidade e origem, por exemplo, das publicações referentes ao assunto avaliado. Assim, isso permite discutir e conhecer com mais precisão a repercussão dos estudos e, consequentemente, das publicações dos pesquisadores da área de estudo analisada: contribuição do sedimento na qualidade da água.

Como já era esperado, os Estados Unidos tem liderado o ranking de publicações e, obviamente, a maior parte dos artigos publicados entre os anos de 2001 e 2011 estão escritos na língua inglesa. A área de estudo em que o tema sedimento está relacionado à qualidade da água que mais se sobressaiu foi a de ciências ambientais e ecologia, seguida pelos estudos em recursos hídricos.

Nesse estudo, o Brasil foi responsável por vinte e duas publicações e duas aconteceram em língua portuguesa. Considerando o potencial do nosso país em relação à quantidade de estudos que ainda podem ser realizados, percebe-se que essa área de estudo necessita de mais profissionais e incentivos por parte das agências financiadoras de pesquisa. 


\section{REFERÊNCIAS BIBLIOGRÁFICAS}

ARINE, D. R. Análise de águas de superfície e sedimentos de rios da região de Iperó, SP, por espectrometria de absorção atômica e por ativação neutrônica. 2000. 127p. Dissertação (Mestrado em Ciências na área de Tecnologia Nuclear Aplicações) - Instituto de Pesquisas Energéticas e Nucleares, IPEN, São Paulo.

BARBOSA, G.S. O desafio do desenvolvimento sustentável. Revista Visões. Rio de Janeiro, 4ạ edição, nํ4, v. 1, jan/jun. 2008. Disponível em: <http://www.fsma.edu.br/visoes/ed04/ 4ed_O_Desafio_Do_Desenvolvimento_Sustentavel_Gisele.pdf $>$. Acesso: em 11 dez. 2012.

BRASIL. Ministério da Saúde. Secretaria de Vigilância em Saúde. Inspeção sanitária em abastecimento de água / Ministério da Saúde, Secretaria de Vigilância em Saúde. Brasília: Ministério da Saúde, 2006. 84p. - (Série A. Normas e Manuais Técnicos).

BRASIL. Portaria Ministério da Saúde no 2914 de 12 de dezembro de 2011. Dispõe sobre os procedimentos de controle e de vigilância da qualidade da água para consumo humano e seu padrão de potabilidade. Ministério da Saúde. Brasília, dezembro, 2011.

CARVALHO, N.O; FILIZOLA JUNIOR N.P; SANTOS P.M.C; LIMA J.E.F.W. 2000. Guia de práticas sedimentométricas. ANEEL, Brasília, $154 \mathrm{p}$.

CEBALLOS, B. S., DANIEL, L. A., BASTOS, R. K. Tratamento de Água para Consumo Humano: Panorama Mundial e Ações do Prosab. 2009. In: Pádua. Desenvolvimento e otimizacao de tecnologias de tratamento de aguas para abastecimento publico, que estejam poluídas com microrganismos, toxinas e microcontaminantes. Rio de Janeiro: ABES, 2009. Cap.1. Disponível em: <http://www.finep.gov.br/prosab/livros/ prosab5_tema\%201.pdf> Acesso em: 03 mar. 2013.

COELHO, M. G.; LIMA, S. C.; MARAGNO, A. L. F.; ALBUQUERQUE, Y. T.; LEMOS, J. C.; SANTOS, C. L.; BRANDÃO, S. L. Contaminação das águas do lençol freático por disposição inadequada de resíduos sólidos urbanos em Uberlândia-MG/Brasil. In: XXVIII Congresso Interamericano de Ingeniería Sanitaria y Ambiental, Cancún. Resumos... Cancún: AIDIS, 2002. Disponível em: http://www.bvsde.paho.org/bvsaidis/mexico26/v-007.pdf.

Acesso em 14 dez. 2012.

COMPANHIA DE TECNOLOGIA DE SANEAMENTO AMBIENTAL CETESB. Água. Relatório de qualidade das águas interiores do Estado de São Paulo. 2006. Disponível em: <http://www.cetesb.sp.gov.br/Agua/relatorios/rios/rel_aguas_i nt_2005/rel_aguas_int_2005.zip>. Acesso em: 23 fev. 2013.

COSTA, C. R.; OLIVI, P.; BOTTA, C. M. R.; ESPINDOLA, E. L.G. A toxicidade em ambientes aquáticos: discussão e métodos de avaliação. Química Nova, v. 31, n. 7, p. 1820-1830, 2008

FERREIRA, A. P; HORTA, M. A. P; CUNHA, C. L. N. Avaliação das concentrações de metais pesados no sedimento, na água e nos órgãos de Nycticorax nycticorax (Garça-da-noite) na Baía de Sepetiba, RJ, Brasil. Revista da Gestão Costeira Integrada, 10 (2):229-241, 2010.
FRANZEN, M. Dinâmica do fósforo na interface águasedimento em reservatórios. 2009. 176p. Tese (Doutorado em Recursos Hídricos e Saneamento Ambiental) Universidade Federal do Rio Grande do Sul - UFRGS, Porto Alegre.

HILACO, S.I. da. Implementação do Plano de Segurança da Água para consumo humano em Portugal. Dissertação de Mestrado. 2012. Disponível em <http://hdl.handle.net/10362/7393>. Acesso em: 03 mar. 2013.

HORTELLANI M. A.; SARKIS J. E.S.; BONETTI, J.; BONETTI, C. Evaluation of mercury contamination in sediments from Santos - São Vicente estuarine System, São Paulo State, Brazil. J Braz Chemistry Society. 2005; 16(6A):1140-9. Disponível em: <http://www.scielo.br/pdf/jbchs/v16n6a/ 27058.pdf>. Acesso em: 23 fev. 2013.

JARDIM, G. M. Estudos ecotoxicológicos da água e do sedimento do Rio Corumbataí, SP. 2004. 126p. Dissertação (Mestrado em Ecologia de Agroecossistemas) - Universidade de São Paulo - USP, Piracicaba.

KUMMROW, F; MAGALHÃES, D; FRANCO, A; UMBUZEIRO, G. A. Blue rayon e teste Salmonella/microssoma na avaliação da qualidade de águas costeiras. Revista Saúde Pública. 40(5), p. 890-897, 2006. Disponível em: < http://www.scielo.br/pdf/rsp/v40n5/20.pdf>. Acesso em: 14 dez.2012.

MORTATTI, J; HISSLER, C; PROBST, J. L. Distribuição de metais pesados nos sedimentos de fundo ao longo da bacia do Rio Tietê. Revista do Instituto de Geociências - USP. Sér. Cient., São Paulo, v.10, n.2, p.3-11, 2010.

ORTIZ, R. As ciências sociais e o inglês. Revista Brasileira de Ciências Sociais - RBCS. v.19, n. 54, p.1-22, 2004.

PATO, J. H., 2011. História das políticas públicas de abastecimento e saneamento de águas em Portugal. Lisboa: ERSAR. Disponível em:<http://www.ersar.pt/website/ ViewContent.aspx?GenericContentld=0\&SubFolderPath $=\% 5 c R$ oot $\% 5 c$ Contents\% $\%$ cSitio $\% 5 c$ MenuPrincipal\%5cDocumentaca 0\%5cPublicacoesIRAR\&Section=MenuPrincipal\&FolderPath $=\%$ 5cRoot\%5cContents\%5cSitio\%5cMenuPrincipal\%5cDocument aCão> Acesso em: 03 mar. 2013.

PAZ, V. P.S; TEODORO, R. E. F; MENDONCA, F. C. Recursos hídricos, agricultura irrigada e meio ambiente. Rev. bras. eng. agríc. ambient., Campina Grande, v. 4, n. 3, dez. 2000. Disponível em $<$ http://www.scielo.br/scielo.php?script=sci_arttext\&pid=S14 15-43662000000300025\&lng=pt\&nrm=iso>. Acesso em 11 dez. 2012 . http://dx.doi.org/10.1590/S141543662000000300025

SAMPAIO, A. C. S. Metais pesados na água e sedimentos dos rios da bacia do Alto Paraguai. 2003. 76p. Dissertação (Mestrado em Saneamento Ambiental e Recursos Hídricos) Universidade Federal de Mato Grosso do Sul - UFMS, Campo Grande. 
SILVA, W. L; MATOS, R. H. R; KRISTOSCH, G. C; MACHADO, W. Variabilidade espacial e sazonal da concentração de elementostraço em sedimentos do sistema estuarino de Santos-Cubatão (SP). Revista Química Nova. V.29, n.2, p.256-263. 2006. Disponível em: < http://quimicanova.sbq.org.br/qn/qnol/2006/ vol29n2/15-AR05120.pdf>. Acesso em: 14 dez.2012.

SILVA, H.M. Língua franca no brasil: inglês, globês ou inglês brasileiro? 2009. Disponível em: <http://veredas.favip.edu.br/ index.php/veredas1/article/viewFile/76/87> Acesso em: Acesso em: 09 dez.2012.

SOUSA, J. K. C. Avaliação de impactos ambientais causados por metais-traço em água, sedimento e material biológico na Baia de São Marcos, São Luís - Maranhão. 2009. 87p. Tese (Doutorado em Química) - Universidade Federal da Paraíba UFPB, Paraíba.

SOUZA, R. A. Avaliação de metais em águas na sub-bacia hidrográfica do rio Ivinhema, Mato Grosso do Sul. 2007. 84p. Dissertação (Mestrado em Tecnologias Ambientais) Universidade Federal do Mato Grosso do Sul - UFMS, Campo Grande.

TAVARES, T. M; CARVALHO, F. M. Avaliação de exposição de populações humanas a metais pesados no ambiente: exemplos do recôncavo baiano. Química Nova, 15(2), 1992.

THE ROYAL SOCIETY. Knowledge, Networks and Nations: Global scientific collaboration in the 21st century. 2011. Disponivel em:

<http://royalsociety.org/uploadedFiles/Royal_Society_Content/ policy/publications/2011/4294976134.pdf> Acesso em: 09 dez.2012.

TRINDADE, W. M. Concentração e distribuição de metais pesados em sedimentos do rio São Francisco entre Três Marias e Pirapora/MG: fatores naturais e antrópicos. 2010. 111p. Dissertação (Mestrado em Geologia) - Universidade Federal de Minas Gerais - UFMG, Belo Horizonte.

WHO - WORD HEALTH ORGANIZATION. Guidelines for drinking - water quality. $3^{\text {rd }}$ ed. Geneva: WHO, 2004. 